\title{
What processes are involved in the appetite response to moderate increases in exercise-induced energy expenditure?
}

\author{
Neil A. King \\ BioPsychology Group, School of Psychology, University of Leeds, Leeds LS2 9JT, UK
}

\begin{abstract}
It is intuitive that an energy deficit induced by exercise induces an automatic increased drive for food (hunger and energy intake). However, the absence of a compensatory increase in energy intake (EI) in response to an exercise-induced increase in energy expenditure (EE) is now well documented. Thus, there is a weak coupling between exercjse-induced increases in EE and EI. One paradox related to the phenomenon of a weak coupling between the exercise-induced $E E$ and EI is the observation of a positive relationship between physical activity and food intake in the long-term free-living situation (i.e. tight coupling between EE and EI). It is possible, therefore, that a period of transition (uncoupling) occurs in the short-term, before a steady-state (coupling) condition is achieved. It is likely that a combination of physiological and behavioural adaptations occur in order to achieve a tight coupling between EE and EI. The precise physiological and behavioural changes that take place to obtain a new equilibrium (i.e. coupling between $\mathrm{EE}$ and $\mathrm{EI}$ ) are still undetermined. The expectation that exercise-induced increases in EE should drive up hunger and food intake tends to be based on the concept of a strong coupling between physiology and behaviour. However, because of the individual's strong volitional control over eating behaviour, the psychological influences on the appetite response to exercise should not be undervalued. The psychological position of the individual (e.g. dietary restraint, food-related cognitions, reasons for exercising) could have a very strong influence on the food intake response to exercise. Misjudgements concerning the energy value of the food (EI) relative to the energy value of the exercise (EE) could be one possibility why exercise fails to be a successful method of weight loss for some individuals.
\end{abstract}

Exercise: Physical activity: Food intake

\section{Absence of compensation in energy intake}

Eating and exercise can be considered as two independent behavioural determinants of energy balance. It is possible that moderate increases in exercise-induced energy expenditure (EE) interact with eating to influence energy balance. One of the main issues concerning the relationship between exercise-induced changes in EE and appetite is: does the body have a rapidly acting mechanism which matches energy intake (EI) to a calculated energy balance? According to a model proposed by James Hill (Hill et al. 1995) 'individuals who are theoretically most responsive to physiological cues of hunger and satiety (i.e. dietary unrestrained and lean) would respond to increased physical activity by increasing their food intake'. This suggests that exercise induces an automatic physiological drive in hunger and food intake. It is intuitive that an energy deficit induced by a period of exercise would be compensated for by an increase in food intake following the exercise. This intuition possibly originates from the evidence that the body has very sensitive compensatory mechanisms to oppose an energy deficit induced by food restriction (skipping of a meal) or an energy differential (between two meals of different sizes) giving rise to hunger and increased food intake (Lawton et al. 1993; Green et al. 1994; Delargy et al. 1995). Recently, this method of inducing an energy deficit (food deficit) has been compared with exercise (another method of inducing an energy deficit) using the same subjects (Hubert et al. 1998). The results confirmed that food deprivation (meal omission) significantly increased hunger and energy intake, whereas the exercise-induced energy deficit did not. This suggests that the appetite responses to food deprivation are quite different from the appetite responses induced by an acute bout of exercise. 
Expectations that exercise should induce a compensatory increase in food intake could also originate from the belief that energy balance is tightly regulated (i.e. EE drives EI). For example, Jean Mayer (Mayer et al. 1956) stated that 'the regulation of food intake functions with such flexibility that an increase in energy output due to exercise is automatically followed by an equivalent increase in caloric intake'. However, the evidence is counterintuitive. The phenomenon of an absence of a compensatory increase in $\mathrm{EI}$ in response to acute exercise-induced increases in $\mathrm{EE}$ is now well documented (Reger et al. 1986; Reger \& Alison, 1987; Thompson et al. 1988; Kissileff et al. 1990; King et al. 1994, 1995; King \& Blundell, 1995; Imbeault et al. 1997; Westerterp-Plantenga et al. 1997; Lluch et al. 1998). Only a few studies have reported a significant increase in EI in response to an acute bout of exercise (Verger et al. 1992; Lavin et al. 1998). Most of the exerciseintervention studies involve the limited measurement of EI at the meal immediately following the exercise only (usually a laboratory test meal) and relatively small exercise-induced increases in EE (1-2 MJ). However, recently, the effects of increased $\mathrm{EE}$ on total daily EI were measured in a whole-body calorimeter, showing that an increase in EE of $2 \mathrm{MJ}$ did not affect EI during the whole day (Gilsenan et al. 1998). Even with larger increases in exercise-induced EE (approximately $4.5 \mathrm{MJ}$ ), and measurement for $1 \mathrm{~d}$ after the physical-activity-induced increase in EE, EI remained unaffected by exercise (King et al. 1997a). Indeed, there are examples of an uncoupling between EE and EI existing for several weeks (Woo et al. $1982 a, b$ ) and even months (Westerterp et al. 1991). Most of the evidence, therefore, suggests that there is no compensatory increase in food intake which results in a weak coupling between EE and EI (for a review, see King et al. 1997b).

\section{What processes could be involved in inducing a coupling between energy expenditure and energy intake?}

It is likely that the weak coupling between exercise-induced $\mathrm{EE}$ and EI (i.e. energy deficit) as a result of the lack of compensation could not continue indefinitely. That is, the body could not tolerate a persistent loss in body weight. Thus, at some stage during the weight loss some mechanism(s) must 'kick in' in order to prevent further weight loss. What behavioural and/or physiological mechanisms could be responsible for such compensatory processes? At what stage (and under what conditions) do such compensatory mechanisms occur? During the imbalance between $\mathrm{EE}$ and $\mathrm{EI}$ there are several physiological consequences that occur in response to a loss in body weight. This period of imbalance has been labelled as the 'transition period' (Hill et al. 1995). One of the major physiological consequences of weight loss is the compensatory reduction in resting metabolic rate (Forbes \& Welle, 1983; Leibel \& Hirsch, 1984; Leibel et al. 1995). There is also an increase in maximum $\mathrm{O}_{2}$ uptake in response to exercise (Leiber et al. 1989; Katzel et al. 1995) which would have the 'knock on' effect of reducing the exercise-induced EE, especially if the volume (intensity and/or duration) of exercise remained unchanged. Another effect of the reduction in body weight would be to reduce the net exercise-induced $\mathrm{EE}$ (Weigle, 1988). However, taking these physiological changes collectively, it is unlikely that they could be entirely responsible for achieving a coupling between EE and EI (steady-state), i.e. a constant body weight (see Fig. 1). It is more likely that behavioural processes are also involved (i.e. a combination of physiology and behaviour). However, it has been suggested that some individuals may become 'energy efficient' in response to increases in the volume (intensity and/or duration) of exercise (Westerterp \& Saris,

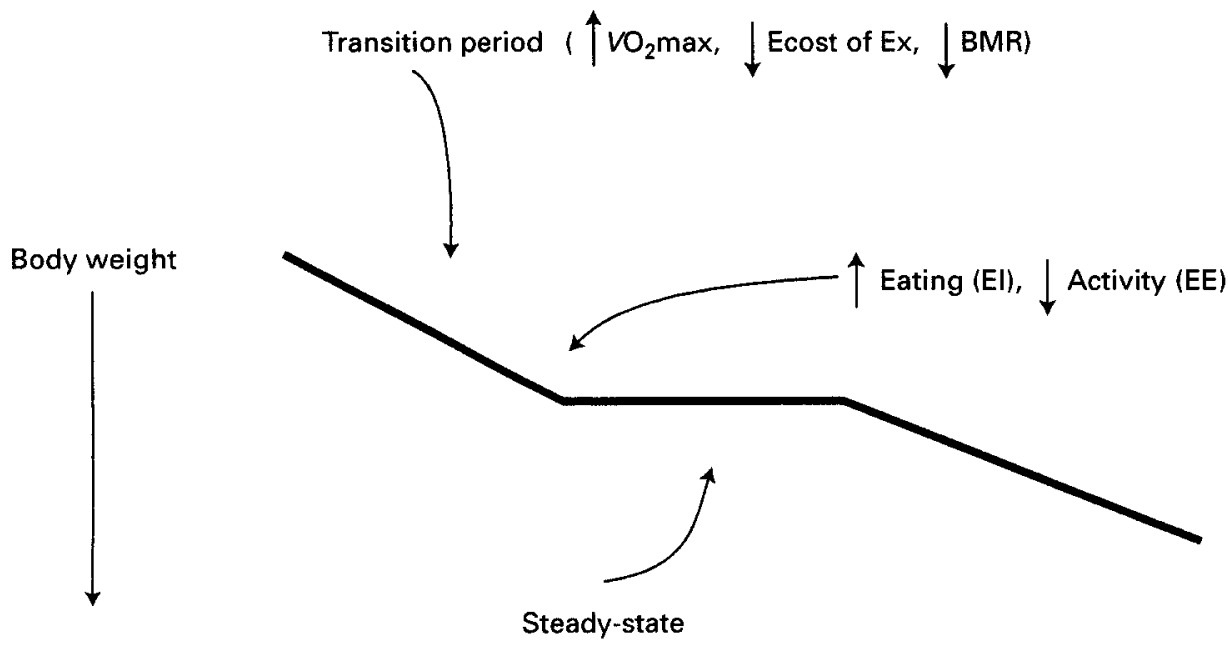

Exercise

Fig. 1. A model to describe the possible physiological and behavioural processes during the weak coupling between energy expenditure (EE) and energy intake (EI) (transition period) before the coupling is achieved (steady-state). $\mathrm{VO}_{2}$ max, maximum $\mathrm{O}_{2}$ uptake; Ecost of Ex, energy cost of exercise. 
1991), producing a discrepancy between the predicted and actual weight-loss responses. It is possible, therefore, that the physiological processes (i.e. reduced resting metabolic rate, reduced exercise-induced $\mathrm{EE}$ ) have the combined effect of gradually reducing the total EE (hence the differential between $\mathrm{EE}$ and $\mathrm{EI}$ ) until a steady-state (balance between $\mathrm{EE}$ and $\mathrm{EI}$ ) is reached.

If physiological processes alone could not account for the steady-state conditions, what potential behavioural processes could be involved? There are only two behavioural responses (or a combination of the two) that could take place to prevent the continuing reduction in body weight (see Fig. 1): first, a compensatory increase in EI (i.e. increased food intake), and second a reduction in $\mathrm{EE}$ (i.e. reduction in physical activity). Although a reduction in activity during the non-exercise time is possible, there is evidence to suggest that individuals do not compensate for the increase in exercise-induced EE by becoming more sedentary (Almeras et al. 1991; Westerterp et al. 1991; Gilsenan et al. 1998). Regarding the potential changes in eating behaviour, there are a number of methods by which EI can be increased (see Table 1).

Eating (meal patterns, food choice etc.) is a behaviour which has been built up over many years and is controlled by physiological limits (e.g. pre-absorptive factors) and social convention (Blundell \& King, 1996). From a behavioural point of view, therefore, the potential methods of increasing EI are likely to involve a mandatory amount of adaptation; for example, the consumption of larger amounts of food within a single eating episode and increasing the frequency of eating (i.e snacking between meals) would involve some behavioural adaptation. The option of increasing energy density would probably be the least 'attractive' method, since for most foods there is a positive relationship between their energy density $(\mathrm{kJ} / \mathrm{g})$ and their fat content (Poppitt \& Prentice, 1995) which also tend to be less satiating (Blundell et al. 1995).

Fluid intake is a logical method of increasing EI, since exercise induces the drive for fluid, hence the ability to consume large volumes of energy-containing drinks (i.e. energy-rich). This fluid-related compensatory process links well with the observation that exercise induces an automatic increase in thirst and fluid intake (Westerterp-Plantenga et al. 1997). Interestingly, the biological system is sensitive to exercise-induced deficits in fluid but not exercise-induced energy deficits, suggesting that the body has an overriding priority to maintain short-term fluid balance, but not energy balance. One possible source of compensatory increases in EI is, therefore, via the consumption of energy-rich, easy-toingest fluids. Recently, a novel study compared the appetite response following a bout of exercise with the appetite response following a sauna (Westerterp-Plantenga et al. 1997). The sauna served as a good comparison since the dehydration and hyperthermia induced by the sauna are not

Table 1. Possible methods of increasing energy intake

Increase food intake within an eating episode

Increase frequency of eating episodes

Increase energy density $(\mathrm{kJ} / \mathrm{g})$ of foods

increase intake of energy-rich fluids accompanied by a considerable, temporary increase in EE. As expected, thirst and fluid intake were significantly increased following the exercise and sauna conditions, compared with rest. The results also showed that, although total EI did not increase, the liquid: solid EI increased significantly after exercise and sauna (see Table 2 ).

Finally, when considering the weak coupling between exercise-induced EE and EI, there appears to be a paradox with the observation that habitually physically-active individuals (with high $\mathrm{EE}$ ) have correspondingly habitual high EI, i.e. there is a positive relationship between physical activity and food intake in the long-term (Maughan et al. 1989; see Fig. 2).

Returning to the transition-steady-state model (Fig. 1), the key issue concerns the behavioural and physiological responses of the sedentary individuals (running distance of $0 \mathrm{~m} /$ week) if they are trained to levels similar to those of the more-active individuals (running distance of $>40 \mathrm{~m} /$ week). The more-active individuals were probably sedentary (or less active) at some stage, hence they are likely to have already experienced the transition stage in order to reach the steady-state condition in which EE matches EI. These physically-active individuals have probably learned how to change their eating behaviour to compensate for their correspondingly-high EE (Saris, 1997). In light of the potential changes in eating behaviour that could occur together with the physiological consequences of the weak coupling, it is possible that at some stage a combination of psychological and physiological processes is involved. The psychobiological threshold at which such compensatory mechanisms play a role (and their relative contribution) has yet to be determined.

\section{Exercise and carbohydrate intake}

So far the discussion has been related to the effects of increases in exercise-induced EE on the quantity of food intake (i.e. EI). What about the potential effects of exercise on the quality (i.e. nutrient mix) of the diet? This concerns the possibility that exercise induces a physiological drive for carbohydrate caused by a greater reduction in glycogen reserves (relative to fat). This hypothesis originates from nutrient balance studies showing that the EI response is more sensitive to manipulations in carbohydrate balance than fat balance, as a result of the large differential in the magnitude of the ability of the body to store each of these two macronutrients (Flatt, 1987). Indeed, Flatt (1987) hypothesized that 'physical exertion may induce a preference for carbohydrate foods over fat containing foods,

Table 2. Energy intake (MJ), solid: liquid energy intake and macronutrient $(\% \mathrm{MJ})$ intake immediately following periods of rest, cycling and sauna in two groups ( 1 and 2 ) of individuals (Adapted from Westerterp-Plantenga et al. 1997)

\begin{tabular}{|c|c|c|c|c|c|c|}
\hline Group & & $\begin{array}{l}\text { Energy } \\
\text { intake }\end{array}$ & $\begin{array}{l}\text { Solid: liquid } \\
\text { intake }\end{array}$ & Carbohydrate & Protein & Fat \\
\hline 1 & Rest & 31 & $70: 30$ & 67 & 14 & 19 \\
\hline 1 & Cycling & 23 & $30: 70$ & 77 & 13 & 10 \\
\hline 2 & Rest & 26 & $72: 28$ & 55 & 18 & 26 \\
\hline 2 & Sauna & 29 & $45: 55$ & 64 & 16 & 20 \\
\hline
\end{tabular}




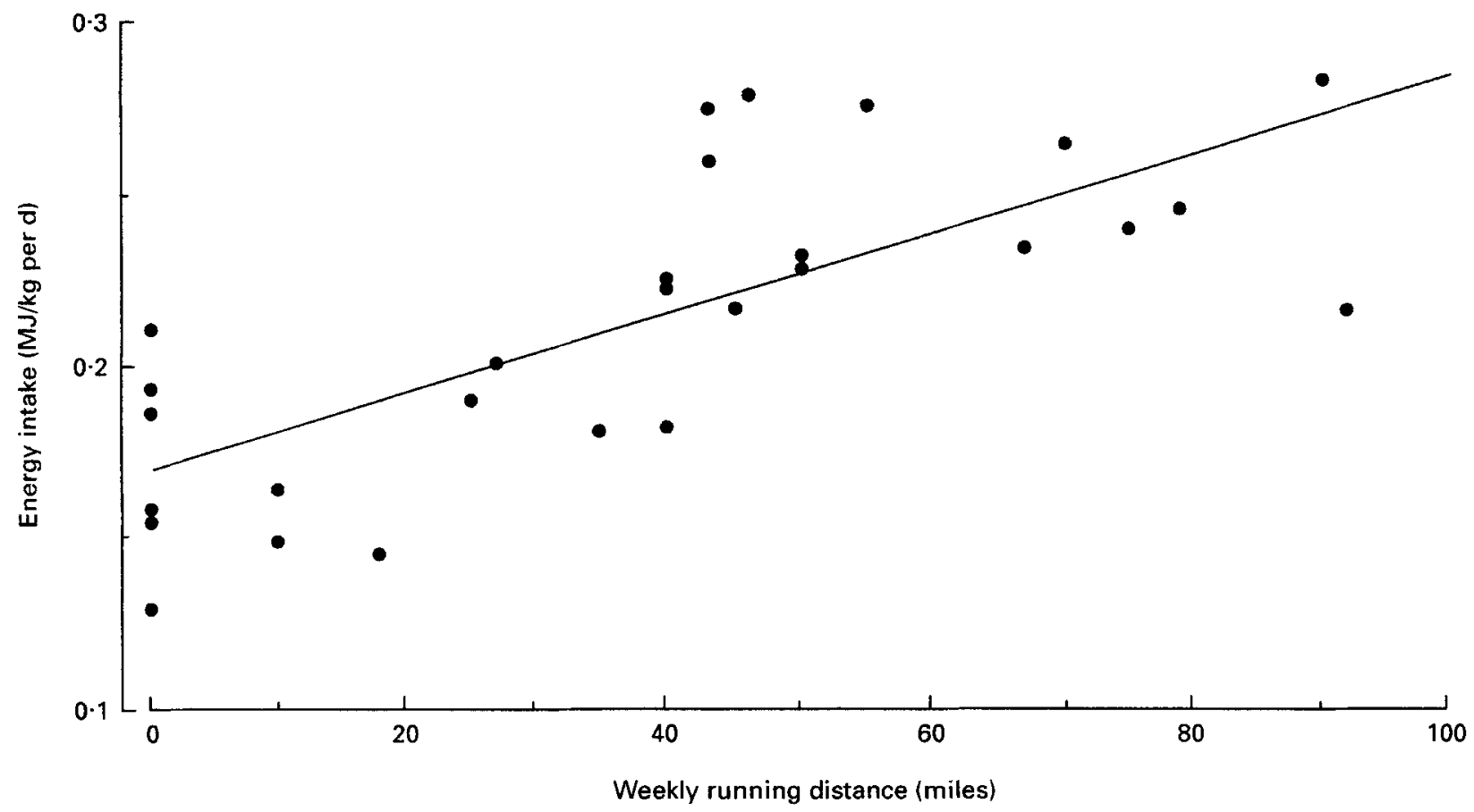

Fig. 2. The relationship between physical activity (measured by miles/week run) and food intake (relative to body weight). (Adapted from Maughan ef al. 1989.)

because physical effort depletes glycogen reserves more than fat reserves'. However, this proposal of a strong link between physiologically-induced changes and behaviour ignores the concept that food choice can also be strongly influenced by environmental contingencies and psychological determinants (Blundell, 1991). In fact, in the short-term, changes in carbohydrate selection have been difficult to demonstrate. Most short-term studies show that a single bout of exercise fails to have an effect on food selection (Reger et al. 1986; Reger \& Alison, 1987; Thompson et al. 1988; King et al. 1994; Tremblay et al. 1994; King \& Blundell, 1995; Imbeault et al. 1997; Gilsenan et al. 1998). Eating behaviour (in particular nutrient selection), therefore, is resistant to short-term changes in exerciseinduced $\mathrm{EE}$.

The resistance of eating behaviour to short-term exerciseinduced changes in metabolism is in line with other studies which have induced large changes in EE and substrate metabolism, but shown small and non-significant changes in food intake (Stubbs et al. 1995a,b). Even when exercise was combined with a dietary regimen to induce large changes in glycogen stores, no significant changes in food and nutrient consumption were found (Snitker et al. 1997). Although most of the evidence suggests that exercise has no effect on nutrient intake, there are a few studies showing changes in nutrient selection due to acute (Verger et al. 1992, 1994; Westerterp-Plantenga et al. 1997) and chronic (Wood et al. 1982; Jansenn et al. 1989) exercise interventions. With the exception of the Verger et al. (1994) study, these studies demonstrated that carbohydrate intake increased in response to exercise. This observation of an increase in carbohydrate intake could be due to physiologically-induced (glycogen depletion) factors. However, it is also possible that the nutrient-specific changes are an artifact of consuming carbohydrate-rich fluids during and after exercise.

Indeed, one example of exercise increasing carbohydrate intake via increased fluid intake is in a study by Thompson et al. (1988). In this study, exercise induced an increase in carbohydrate intake (compared with a period of rest) only when the liquid-source foods (i.e. carbohydrate-rich drinks) were included in the analysis. In a study by Westerterp-Plantenga et al. (1997) two methods of inducing dehydration (sauna and exercise) produced significant increases in carbohydrate intake and the liquid: solid intake (see Table 2). It is possible that individuals selected foods on the basis of their ease of digestion (sensory and/or texture factor) rather than a glycogen-depleted-induced drive for carbohydrate intake (biological factor). However, this is one mechanism (consumption of energy-rich fluids) by which physically-active individuals are able to increase their carbohydrate intake (whilst simultaneously compensating for their high EE).

\section{The strong influence of psychological factors on the energy intake response to exercise}

The intuitive view that exercise induces an automatic drive for food focuses on the influence of physiological changes on behaviour and ignores the concept that psychological factors could influence eating behaviour as much as biological factors (Schlundt et al. 1990). If any exerciseinduced physiological changes did occur, it is possible that these changes could be outweighed by different psychological and cognitive positions. Cognitive and psychological factors are, therefore, very important when considering the relationship between exercise, appetite and energy balance. 
Cognitive factors include dietary status (e.g. the tendency to diet), attitudes and beliefs (e.g. 'exercise makes you hungry') and personal objectives of exercising (e.g. exercise to lose weight). The idea that an individual's psychological position could possibly influence the eating response to exercise was first suggested by Hill et al. (1995); they stated that 'possibly the magnitude of dietary compensation in response to exercise is related more to cognitive factors than physiological stimuli'. Dietary restraint (defined as the tendency to restrict food intake consciously in order to prevent weight gain or to promote weight loss; Herman \& Mack, 1975; Herman \& Polivy, 1975) is one example of a psychological position. One hypothesis related to dietary restraint is that the intent to diet may be disrupted by events such as preloads of alcohol or dysphoric emotions. This phenomenon is related to the disinhibition of cognitive control of eating behaviour and leads to episodes of overeating. It is possible (as suggested by the Hill et al. (1995) model) that exercise per se serves as a disinhibitor in a similar way to alcohol, for example. Few studies have actually examined the influence of psychological position on the relationship between exercise and food intake. Recently, Lluch et al. (1998) compared the effects of exercise on EI in a group of dietary unrestrained females with a group of dietary restrained females. There was a significant positive relationship between EI and dietary restraint following a period of no exercise (rest), but not after an acute bout of exercise. In the absence of exercise (i.e. following rest), therefore, individuals with higher dietary restraint had the highest energy intakes. This is counterintuitive, since usually there is a negative association between dietary restraint and EI (Klesges et al. 1992; French et al. 1994). However, one interpretation of the data from the study of Lluch et al. (1998) is that following an acute bout of exercise the deliberate control over eating (i.e. dietary restraint) was maintained, whereas it was 'disrupted' in the absence of exercise. Exercise therefore, appeared to act as a 'controller' of EI, whereas in the absence of exercise it appeared that these females relaxed their control of food intake. It is possible that dietary-restrained individuals use exercise as a means of 'controlling' their eating, hence their frequency of exercise may also be correspondingly high (Kanarek et al. 1995).

An individual's personal objectives related to exercise (e.g. reasons for exercising) could have an important influence on the appetite response to exercise. An overweight person exercising in an attempt to lose weight may have a completely different food intake response to exercise compared with an athlete competing in a series of consecutive endurance events with the need to replace energy (and carbohydrate) stores. It should be kept in mind, therefore, that the deliberate and volitional control over eating behaviour could have a significant influence on the food intake response to exercise.

In light of the evidence showing a weak coupling between exercise-induced EE and EI, exercise should be a successful method of weight loss. However, in some cases this is not so, and exercise fails to induce the expected reductions in body weight. It is possible that food is perceived as a reward for exercise, which may have the net effect of wiping out the beneficial (energy-deficit-inducing) effects of exercise. The idea that exercise allows a free rein to reward oneself by eating high-energy dense (palatable) foods after exercise has recently been refuted by data from three studies showing that consumption of high-fat energydense foods after exercise completely reversed the shortterm energy deficit usually observed following a bout of high-intensity exercise (Tremblay et al. 1994; King \& Blundell, 1995; King et al. 1996).

Due to the slow rate of exercise-induced EE relative to the rate of EI (Blundell \& King, 1998), some individuals possibly fail to make appropriate adjustments in behaviours (exercise and eating). For example, the energy value of exercise (EE) may be overestimated relative to the energy value of food (EI). Thus, misconceptions concerning the relationship between exercise and appetite could influence exercise and eating behaviours, and may also contribute to the lack of success that is associated with exercise as a method of weight control.

\section{Conclusion}

Most of the evidence suggests that exercise does not generate an automatic increase in hunger or food intake. Hence, the weak coupling between exercise-induced increases in $\mathrm{EE}$ and $\mathrm{EI}$ is a robust phenomenon. It is unlikely that the uncoupling between exercise-induced EE and EI can continue indefinitely. Physiological and behavioural adaptations must take place to prevent a persistent energy deficit. It is likely that the period of weak coupling (transition) is followed by a period in which there is coupling between $\mathrm{EE}$ and El (steady-state). Despite the evidence of a weak coupling between EE and EI, in certain susceptible individuals the strong volitional control over eating behaviour may have an important impact. Miscalculations concerning the exercise and eating behaviours, including the perception of food as a reward for exercise, may result in a reversal of the acute energy deficit. Thus, the psychological position of the individual could have a significant influence on the appetite response to exercise. Exercise-induced changes also have the potential to alter food and nutrient selection. However, most of the evidence suggests that eating behaviour is resistant to short-term perturbations in exercise-induced increases in $\mathrm{EE}$ and changes in metabolism.

\section{Acknowledgement}

I am grateful to John Blundell for his scientific discussion on this paper.

\section{References}

Almeras N, Mimeault N, Serresse O, Boulay MR \& Tremblay A (1991) Non-exercise daily energy expenditure and physical activity pattern in male endurance athletes. European Journal of Applied Physiology 63, 184-187.

Blundell JE (1991) The biology of appetite. Clinical Applied Nutrition 1, 21-31.

Blundell JE, Cotton JR, Delargy H, Green S, Greenhough A, King NA \& Lawton CL (1995) The fat paradox: fat-induced satiety signals versus high fat overconsumption. International Joumal of Obesity 19, 832-835. 
Blundell JE \& King NA (1996) Overconsumption as a cause of weight gain: behavioural-physiological interactions in the control of food intake (appetite). In The Origins and Consequences of Obesity, pp. 138-158 [DJ Chadwick and G Cardew, editors]. Chichester: Wiley.

Blundell JE \& King NA (1998) Effects of exercise on appetite control: loose coupling between energy expenditure and energy intake. International Joumal of Obesity 22, 522-529.

Delargy HD, Burley VJ, Sullivan KR, Fletcher RJ \& Blundell JE (1995) Effects of different soluble:insoluble fibre ratios at breakfast on 24-h pattern of dietary intake and satiety. European Journal of Clinical Nutrition 49, 754-766.

Flatt JP (1987) Dietary fat, carbohydrate balance, and weight maintenance: effects of exercise. American Journal of Clinical Nutrition 45, 296-306.

Forbes GB \& Welle SL (1983) Lean body mass in obesity. International Journal of Obesity 7, 99-107.

French SA, Jeffery RW \& Wing RR (1994) Food intake and physical activity: a comparison of three measures of dieting. Addictive Behaviour 19, 401-409.

Gilsenan MB, Murgatroyd PR, Leahy FE, Goldberg G \& Prentice AM (1998) The response of energy intake and macronutrient balance to manipulations of physical activity levels in lean men. Proceedings of the Nutrition Society 57, 19A.

Green SM, Burley SM \& Blundell JE (1994) Effect of fat- and sucrose-containing foods on the size of eating episodes and energy intake in lean males: potential for causing overconsumption. European Journal of Clinical Nutrition 48, $547-555$.

Herman CP \& Mack D (1975) Restrained and unrestrained eating. Journal of Personality 43, 647-660.

Herman CP \& Polivy J (1975) Anxiety, restraint and eating behaviour. Journal of Abnormal Psychology 84, 666-672.

Hill JO, Melby C, Johnson SL \& Peters JC (1995) Physical activity and energy requirements. American Joumal of Clinical Nutrition 62, Suppl., 1059S-1066S.

Hubert P, King NA \& Blundell JE (1998) Uncoupling the effects of energy expenditure and energy intake: appetite response to shortterm energy deficit induced by meal omission and physical activity. Appetite 31, 9-19.

Imbeault P, Saint-Pierre S, Almeras N \& Tremblay A (1997) Acute effects of exercise on energy intake and feeding behaviour. British Journal of Nutrition 77, 511-521.

Janssen GME, de Graaf CJJ \& Saris WHM (1989) Food intake and body composition in novice athletes during a training period to run a marathon. International Journal of Sports Medicine 10, S17-S21.

Kanarek RB, Ryu M \& Przypek J (1995) Preferences for foods with varying levels of salt and fat differ as a function of dietary restraint and exercise but not menstrual cycle. Physiology and Behavior 57, 821-826.

Katzel LI, Bleecker ER, Colman EG, Rogus EM, Sorkin JD \& Goldberg AP (1995) Effects of weight loss vs aerobic exercise training on risk factors for coronary disease in healthy, obese, middle-aged and older men. Journal of the American Medical Association 274, 1915-1921.

King NA \& Blundell JE (1995) High-fat foods overcome the energy expenditure due to exercise after cycling and running. European Journal of Clinical Nutrition 49, 114-123.

King NA, Burley VJ \& Blundell JE (1994) Exercise-induced suppression of appetite: Effects on food intake and implications for energy balance. European Journal of Clinical Nutrition 48, $715-724$

King NA, Lluch A, Stubbs RJ \& Blundell JE (1997a) High dose exercise does not increase hunger or energy intake in free living males. European Journal of Clinical Nutrition 51, $478-483$.
King NA, Snell L, Smith RD \& Blundell JE (1996) Effects of shortterm exercise on appetite response in unrestrained females. European Journal of Clinical Nutrition 50, 663-667.

King NA, Tremblay A \& Blundell JE (1997b) Effects of exercise on appetite control: implications for energy balance. Medicine and Science in Sports and Exercise 29, 1076-1089.

Kissileff HR, Pi-Sunyer XF, Segal K, Meltzer S \& Foelsch PA (1990) Acute effects of exercise on food intake in obese and nonobese women. American Journal of Clinical Nutrition 52, 240245.

Klesges RG, Isbell TR \& Klesges LM (1992) Relationship between dietary restraint, intake, physical activity and body weight: a prospective analysis. Journal of Abnormal Psychology 101, $668-674$.

Lavin JH, Read NW, Nwajiaku J, Stafford PR \& French S (1998) The effect of exercise on subsequent feeding behaviour. Proceedings of the Nutrition Society 57, 19A.

Lawton CL, Burley VJ, Wales JK \& Blundell JE (1993) Dietary fat and appetite control in obese subjects: weak effects on satiation and satiety. International Journal of Obesity 17, 409-416.

Leibel RL \& Hirsch J (1984) Diminished energy requirements in reduced-obese-patients. Metabolism 33, 164-170.

Leibel RL, Rosenbaum M \& Hirsch J (1995) Changes in energy expenditure resulting from altered body weight. New England Journal of Medicine 332, 621-628.

Lieber DC, Lieber RL \& Adams WC (1989) Effects of run-training and swim-training at similar absolute intensities on treadmill VO2max. Medicine and Science in Sports and Exercise 21, 655-661.

Lluch A, King NA, Lipsey Z \& Blundell JE (1998) Comparison of the short-term effects of exercise on food hedonics and food consumption in dietary restrained and unrestrained females. Proceedings of the Nutrition Society 57, $20 \mathrm{~A}$.

Maughan RJ, Robertson JD \& Bruce AC (1989) Dietary energy and carbohydrate intakes of runners in relation to training load. Proceedings of the Nutrition Society 48, 170A.

Mayer J, Roy P \& Mitra KP (1956) Relationship between caloric intake, body weight and physical work: studies in an industrial male population in West Bengal. American Journal of Clinical Nutrition 4, 169-175.

Poppitt SD \& Prentice AM (1995) Energy density of diets and obesity. International Journal of Obesity 19, Suppl., S20-S26.

Reger WE \& Alison TG (1987) Exercise and appetite. Medicine and Science in Sports and Exercise 19, S38.

Reger WE, Allison TA \& Kurucz RL (1986) Exercise, postexercise metabolic rate and appetite. Sport Health and Nutrition 2, 117-123.

Saris WHM (1997) Limits of human endurance: lessons from the tour de France. In Physiology, Stress and Malnutrition: Functional Correlates and Nutritional Intervention, pp. 451-462 [JM Kinney and HN Tucker, editors]. Philadelphia and New York: Lippincott-Raven.

Schlundt DG, Hill JO, Sbrocco T, Pope-Cardle J \& Kasser T (1990) Obesity: a biogenetic or biobehavioural problem. International Journal of Obesity 14, 815-828.

Snitker S, Larson DE, Tataranni PA \& Ravussin E (1997) Ad libitum food intake in humans after manipulation of glycogen stores. American Journal of Clinical Nutrition 65, 941-946.

Stubbs RJ, Harbron CG, Murgatroyd PR \& Prentice AM (1995a) Covert manipulation of dietary fat and energy density: effect on substrate flux and food intake in men eating ad libitum. American Journal of Clinical Nutrition 62, 316-329.

Stubbs RJ, Ritz P, Coward WA \& Prentice AM (1995b) Covert manipulation of the ratio of dietary fat to carbohydrate and energy density: effect on food intake and energy balance in freeliving men eating ad libitum. American Journal of Clinical $\mathrm{Nu}_{\mathrm{H}}$ trition 62, 330-337. 
Thompson DA, Wolfe LA \& Eikelboom R (1988) Acute effects of exercise intensity on appetite in young men. Medicine and Science in Sports and Exercise 20, 222-227.

Tremblay A, Almeras N, Boer J, Kranenbarg EK \& Despres JP (1994) Diet composition and postexercise energy balance. American Journal of Clinical Nutrition 59, 975-979.

Verger P, Lanteaume MT \& Louis-Sylvestre J (1992) Human intake and choice of foods at intervals after exercise. Appetite 18, 93-99.

Verger P, Lanteaume MT \& Louis-Sylvestre J (1994) Free food choice after acute exercise in men. Appetite 22, 159-164.

Weigle DS (1988) Contribution of decreased body mass to diminished thermic effect of exercise in reduced-obese men. International Journal of Obesity 12, 567-578.

Westerterp-Plantenga MS, Verwegen CRT, Ijedema MJW, Wijckmans NEG \& Saris WHM (1997) Acute effects of exercise or sauna on appetite in obese and nonobese men. Physiology and Behavior 62, 1345-1354.
Westerterp KR \& Saris WHM (1991) Limits of energy turnover in relation to physical performance, achievement of energy balance on a daily basis. Journal of Sports Science 9, 1-5.

Westerterp KR, Verboeket-Van de Venne WPHG, Meijer GAL \& ten Hoor F (1991) Self-reported intake as a measure for energy intake: a validation against doubly labelled water. In Obesity in Europe 91, pp. 17-22 [G Ailhaud, editor]. London: John Libbey \& Co.

Woo R, Garrow JS \& Pi-Sunyer FX (1982a) Effect of exercise on spontaneous calorie intake in obesity. American Journal of Clinical Nutrition 36, 470-477.

Woo R, Garrow JS \& Pi-Sunyer FX (1982b) Voluntary food intake during prolonged exercise in obese women. American Journal of Clinical Nutrition 36, 478-484.

Wood PD, Haskell WL \& Terry RB (1982) Effects of a two-year running program on plasma lipoproteins, body fat and dietary intake in initially sedentary men. Medicine and Science in Sports and Exercise 14, 104 Abstr. 